\section{omi}

OAK RIDGE NATIONAL LABORATORY
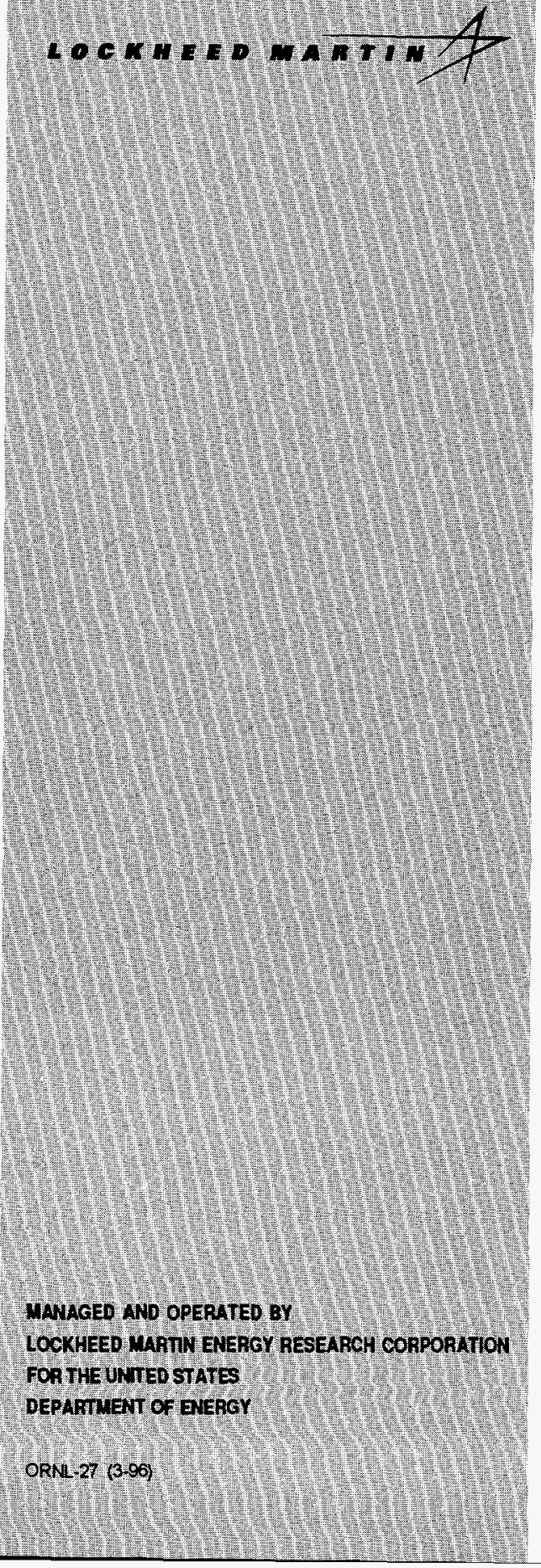

ORNL/TM-13235

\section{TRACE GAS CONCENTRATOR FY 1995 SUMMARY REPORT}

John B. Andriulli

Andrew J. Szady Jr.

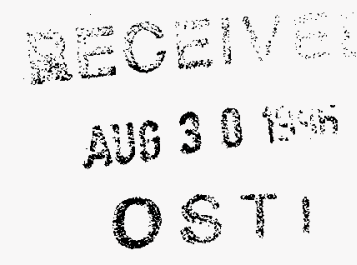

Oak Ridge National Laboratory

May 1996

\author{
Prepared by \\ Oak Ridge National Laboratory \\ Oak Ridge, Tennessee 37831-6285 \\ Managed by \\ LOCKHEED MARTIN ENERGY RESEARCH Corp. \\ for the \\ U.S. DEPARTMENT OF ENERGY \\ under contract DE-AC05-95OR22464

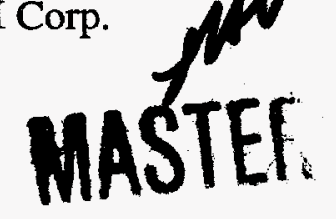

DETREUTION OF THIS DOCUMENT IS UNUMMTES 


\section{DISCLAMER}

This report was prepared as an account of work sponsored by an agency of the United States Government. Neither the United States Government nor any agency thereof, nor any of their employees, makes any warranty, express or implied, or assumes any legal liability or responsibility for the accuracy, completeness, or usefulness of any information, apparatus, product, or process disclosed, or represents that its use would not infringe privately owned rights. Reference herein to any specific commercial product, process, or service by trade name, trademark, manufacturer, or otherwise does not necessarily constitute or imply its endorsement, recommendation, or favoring by the United States Government or any agency thereof. The views and opinions of authors expressed herein do not necessarily state or reflect those of the United States Government or any agency thereof. 


\section{DISCLAIMER}

Portions of this document may be illegible electronic image products. Images are produced from the best available original document. 


\title{
TRACE GAS CONCENTRATOR FY 1995 SUMMARY REPORT
}

\author{
John B. Andriulli
}

Andrew J. Szady Jr.

Oak Ridge National Laboratory

May 1996

\author{
Prepared by \\ Oak Ridge National Laboratory \\ Oak Ridge, Tennessee 37831-6285 \\ Managed by \\ LOCKHEED MARTIN ENERGY RESEARCH CORP. \\ for the \\ U.S. DEPARTMENT OF ENERGY \\ under contract DE-AC05-96OR22464
}




\section{TRACE GAS CONCENTRATOR \\ FY 1995 SUMMARY REPORT}

\section{SUMMARY}

This report summarizes the accomplishments of the Trace Gas Concentrator Technology Demonstration Project during FY 1995 and through February 1996. The purpose of the activity was to demonstrate proof of principle of a system that concentrates airborne substances (e.g., chemical agents, explosives, narcotics and their precursors, and pollutants) to aid in their detection.

The following work has been completed:

1. A comprehensive computer model (initiated in FY 1994) was developed for the theoretical prediction of the fluid dynamics and mass concentration of the trace gas concentrator. The trace gas concentrator separates gases with different molecular weights in a mixture. The model predicts the mole fraction distribution of the gases within the rotor, depending upon the machine geometric configuration, rotational speed, inlet mass flow rate, inlet velocity profile, and turbulence characteristics. The model has given very valuable insight into the physical effects associated with design and operational parameters of the hardware. However, concentrator performance test data is currently not available to compare against the model predictions.

2. The gas test stand has been installed and checked out. The gas test stand was designed to control and measure temperatures, pressures, flow rates, and trace gas concentration from outside the spin tank safety containment.

3. An automated computer data acquisition system has been installed and connected to the concentrator test stand. The data acquisition system is needed to record gas and mechanical operations.

4. The concentrator rotor was assembled, without shaft seals, and installed in the spin test tank for balancing. The rotor was balanced for the first two rigid body criticals and operated in air up to $9200 \mathrm{rpm}$. However, the rotor could not be operated in air (without seals) above $9200 \mathrm{rpm}$ because the external rotor windage drag exceeded the drive motor power capacity. Since no other rotor criticals are expected between $9200 \mathrm{rpm}$ and the operating speed of $37,000 \mathrm{rpm}$, little or no additional trim balancing is anticipated. Therefore the rotor balancing has been completed.

5. The concentrator has six lip seals on the shaft for the vacuum and air flow passages. The shaft friction of the original seals was excessive. The drive motor was not capable of turning the rotor at the design speed of $37,000 \mathrm{rpm}$. Even if a larger motor were used, the excess heat generated at the seals would be detrimental to concentration performance in both seal and shaft life. In order to achieve the higher speed necessary for effective gas concentration, the drag of the six seals must be reduced.

The challenge is to find the optimum combination of low seal drag and low casing vacuum such that the sum of seal drag and windage drag at the required operating speed is not detrimental to the mechanical or concentration performance of the machine. Efforts to find the optimum combination were in progress when our carry-over funding ran out. 
New lower tension contact seals were procured and modified. The seal drag was reduced about an order of magnitude. One modified seal was placed in the inlet manifold and successfully operated about 15 minutes up to $9200 \mathrm{rpm}$ without seal or shaft damage. This low-drag seal also held good (low windage drag) vacuum (without shaft rotation) indicating potential for satisfactory operation. It remains now to find the cause of vacuum leakage, from sources other than the seals, to the rotor casing, and to make sure the other five seals work as well as the one tested above. If this can be done without having to tighten the seals, the rotor should be able to run to full operating speed, and then gas performance testing can begin.

6. If the use of the current mechanical lip seal is unsuccessful, an alternate low drag, non-contact, dry gas design concept has been explored. Although dry-gas seals are currently used in systems with higher pressure differential, experts have indicated applicability to moderate vacuum systems such as in the concentrator. However, the use of dry-gas seal technology in the concentrator would require hardware modifications.

\section{BACKGROUND}

There is a growing need to be able to detect trace quantities of various volatile substances contained in air samples such as: chemical agents, explosives, narcotics and their precursors, and pollutants. In general, sensors can be made to identify a target substance; however, there is a threshold concentration level below which the sensors cannot operate effectively. An air sample concentrator is needed that will extend the sensitivity range of today's sensors by providing a large, integrated, concentrated sample to the detector. The concentrator could be used to help detect the presence of nerve gas in enclosed spaces such as subways.

A trace gas concentrator is placed between the sample source and the detector system. Only the concentrated stream is passed to the detector, while the depleted stream is exhausted directly back to the atmosphere. There are several inherent advantages with the use of such a system:

1. Large concentrated samples are available to the detector.

2. Concentration or source amplification of orders of magnitude are possible.

3. Large air volumes can be screened and reduced to sensor sample size.

A schematic of the air flow paths within the trace gas concentrator is shown in Figure 1. Ambient air, containing some heavier than air target molecules, is drawn into the inlet of the rotating center shaft. Once inside, it is forced into the high-speed concentrator rotor where the heavy molecules are pushed toward the rotating wall by centrifugal force. The majority of the air, being lighter, does not make it to the wall but flows axially up the rotor and is expelled out the rotating center shaft near the top of the rotor. The air containing the extracted target heavy molecules is extracted out near the rotor wall by a rotating tube extractor. From here the concentrated sample is passed back through the rotating shaft and out the machine to the detector system. The top extractor is made to rotate in order to eliminate drag, which would disrupt the radial separation process. The length, diameter, and speed of the rotor are a function of the molecular weight difference between the target molecule and air, the air flow rate, the sample size required, and the degree of concentration required.

Originally, the Department of Energy Office of Arms Control, Systems and Technology Division, funded the Trace Gas Concentrator Project to develop, build, and test a concept demonstration unit. In addition to the hardware, a NASA fluid flow model has been modified to predict flow and concentration performance of specific hardware designs. Turbulence has been incorporated into the model to handle the unique flows which 
DWG. NO. K/G 96-185 GSS

(U)

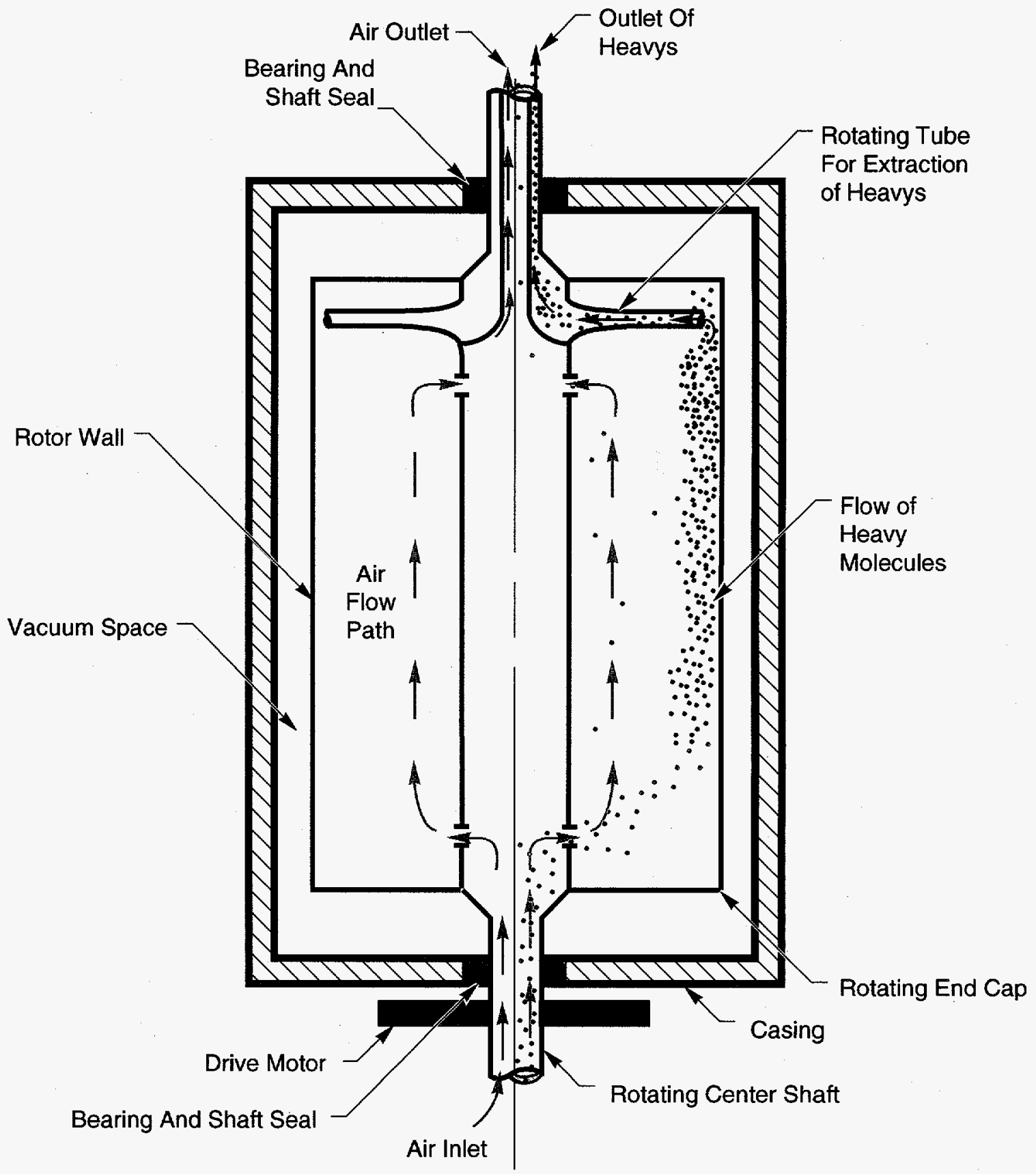

Figure 1. Schematic of Trace Gas Concentrator. 
are expected within this type of device. Two technical papers (References 1 and 2) on the use of the modified model have been presented at technical meetings (ASME and AIAA), and a third is being prepared. We also have a dedicated computer work station to run the flow model, and a very sophisticated software package to graphically present the results.

Due to budgetary constraints, the original sponsor was no longer able to fund the evaluation phase of the Trace Gas Concentrator Project. Consequently, because of the potential commercial applications for devices like this, the Uranium Programs Technology Partnerships Program agreed to sponsor the test and evaluation phase. In addition to the commercial potential for devices like this, the Army and the FAA have expressed an interest in the project and are anxious to see the test results. Once the concept is proven, we feel that a variety of commercial applications are possible. The project is currently at the point of needing actual test data to demonstrate the concept to potential sponsors and to provide performance test data which will enable the computer model to be calibrated. Once the model is calibrated, we will be able to design and predict the performance of concentrators for specific customer's applications. In addition, the test data will provide feedback on the mechanical design of the unit. The current mechanical design has several unique features which are not found in any other device and must be verified by actual mechanical operational testing.

\section{ACCOMPLISHMENTS OF FY 1995 THROUGH FEBRUARY FY 1996}

During the reporting period, the following work has been completed:

\section{Theoretical Model}

A comprehensive computer model (initiated in FY 1994) was developed for the theoretical prediction of the fluid dynamics and mass concentration of the trace gas concentrator. The trace gas concentrator separates gases with different molecular weights in a mixture. The computer model includes a time-accurate full NavierStokes solver, mass transportation with both ordinary and forced diffusion, and turbulence. The model predicts the mole fraction distribution of the heavy gases within the rotor as a function of the machine's geometric configuration, rotational speed, inlet mass flow rate, inlet velocity profile, and turbulence characteristics. When correlated with actual gas test performance data, the theoretical model will be an effective tool for understanding the gas concentration phenomena and will allow the prediction of performance of other configurations and operating conditions. The model was originally developed at NASA and was modified for the concentrator work at the University of Memphis, Mechanical Engineering Department, by Dr. J. D. Mo as reported in References 3 and 4. The model runs on a workstation computer.

\section{Gas Stand}

The gas test stand was installed on the spin test tank as shown in Figs. 2, 3, and 4. The gas test stand, shown schematically in Fig. 5, permits control of vacuum, air flow, and trace gas flow through the concentrator. The gas test stand is designed to control or measure various temperatures, pressures, mass and volumetric flow rates, as well as trace gas concentration at the feed and product ports of the concentrator. All gas stand operations and measurements can be performed from outside the spin tank safety containment. 
DWG. NO. K/G 96-186 GSS

(U)

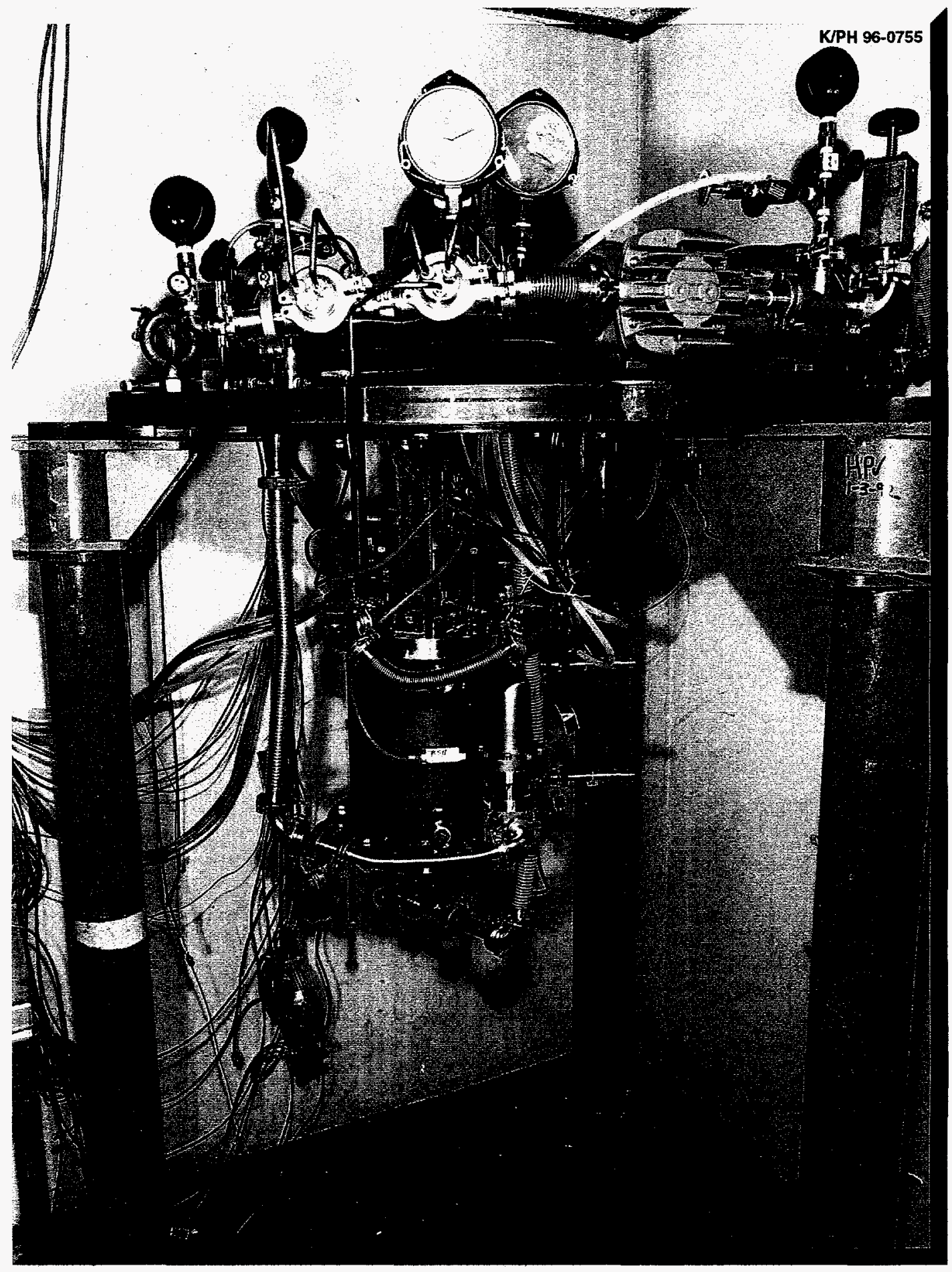

Figure 2. Concentrator and gas test stand on the spin tank lid. 
DWG. NO. KJG 96-187 GSS

(U)

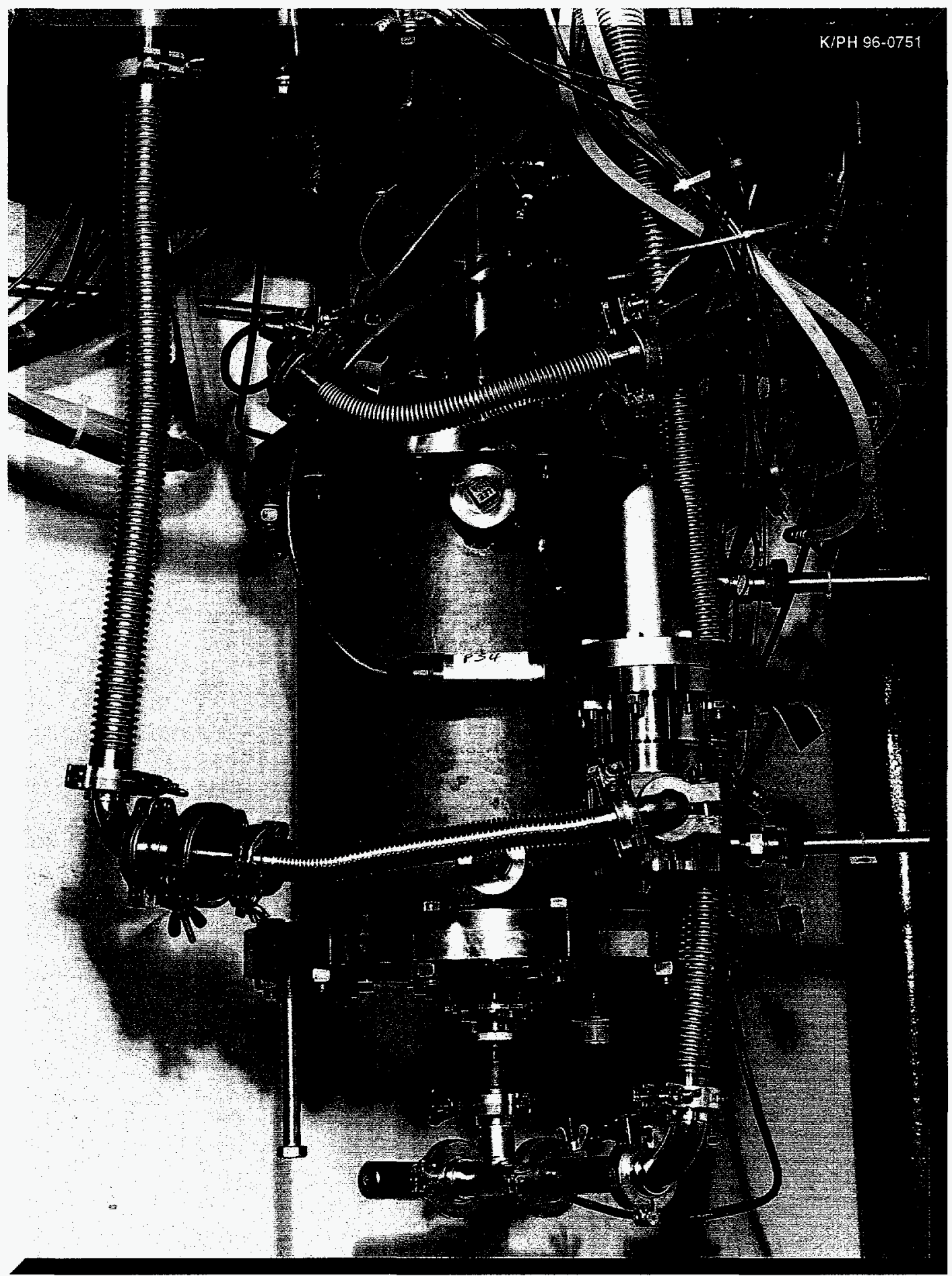

Figure 3. Concentrator mounted under the spin tank lid. 


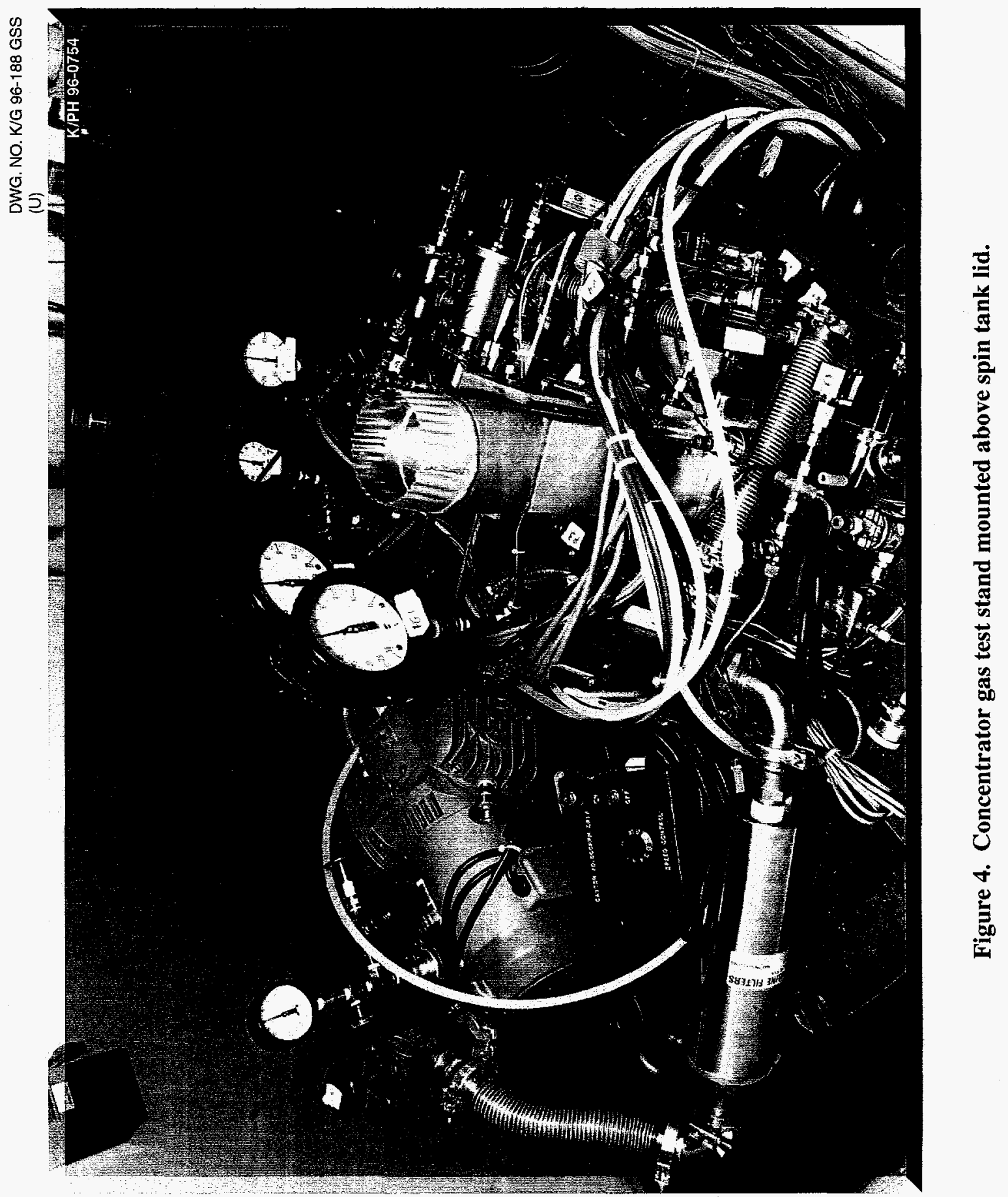




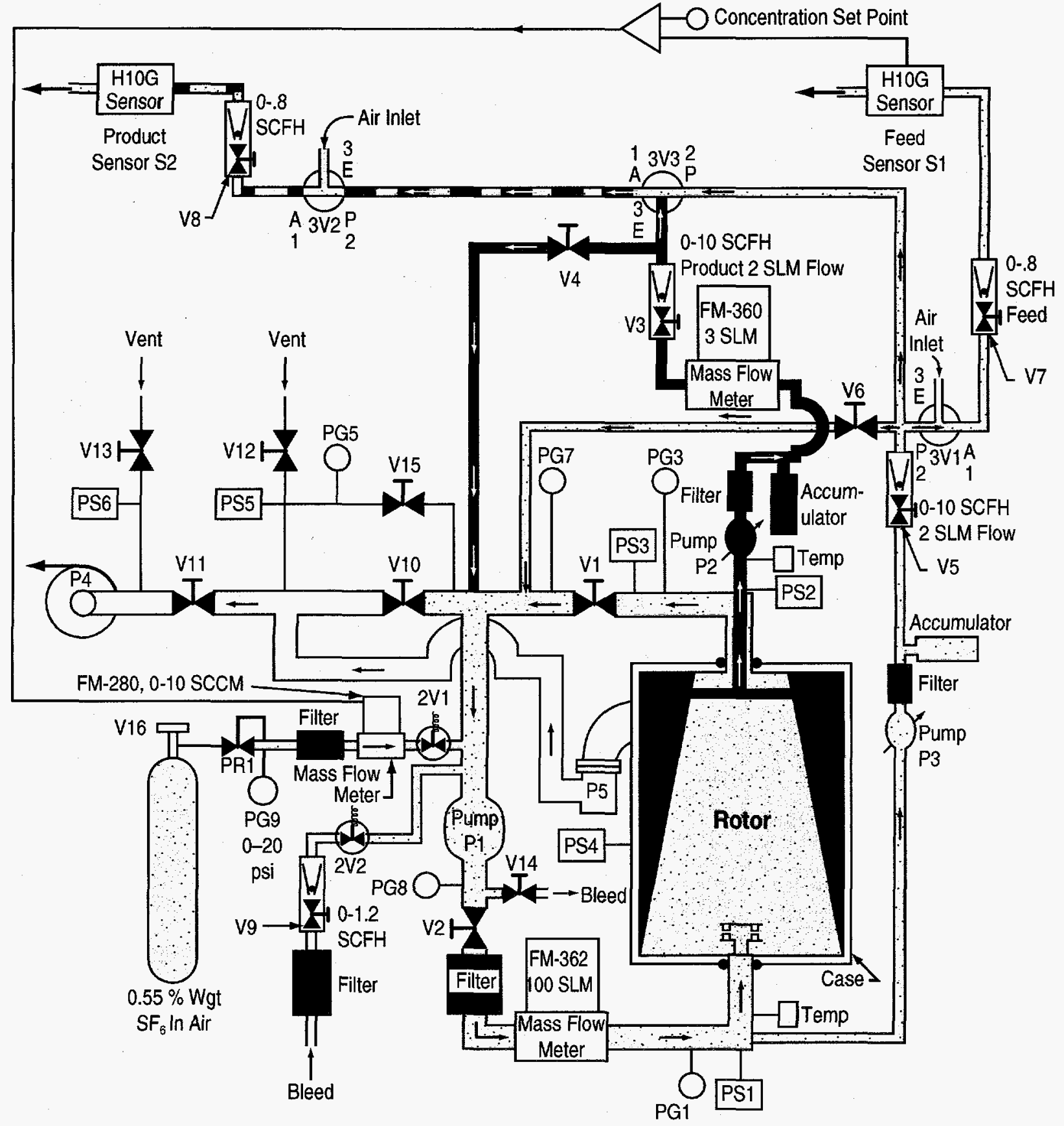

Figure 5. Concentrator Gas Flow Control and Instrumentation Open Loop Concentration Sensing

Manual or Automatic Concentration Control February 9, 1995 


\section{Data Acquisition}

An automated computer data acquisition system, shown in Fig. 6, was installed and connected to the concentrator test stand. In addition to recording gas stand data described above, the data acquisition system is used to record balancing and mechanical operations such as shaft and rotor runout and bearing and damper temperature.

\section{Balancing}

The rotor was assembled without seals and installed in the spin test tank for balancing. The rotor was balanced for the first two rigid body criticals and operated in air up to $9200 \mathrm{rpm}$. The as-built rotor imbalance exceeded 2.5 mils single amplitude (SA) shaft run out at $2250 \mathrm{rpm}$. After balancing, the shaft runout remained within 0.25 mil SA up to $9200 \mathrm{rpm}$. This demonstrated very good vibration control by the viscoelastic dampers used in the concentrator design. The rotor could not be operated in air (without seals) above 9200 rpm because windage drag exceeded the drive motor power capacity.

\section{Seal Drag}

Generally, tight-lip seals allow good vacuum, which results in low windage drag but at the expense of high shaft drag. With loose seals the situation is reversed; poor vacuum with high windage drag, but low shaft seal drag. The challenge is to find the optimum combination of low seal drag and low vacuum such that the sum of seal drag and windage drag at operating speed is a minimum or, at least, less than the drive motor rating. Efforts to find the optimum combination were in progress when funding ran out.

The concentrator has six lip seals on the shaft for vacuum and air flow passages. Friction of the original seals was excessive. The drive motor was not capable of turning the rotor at the design speed of 37,000 rpm. Even if the drive motor could supply enough torque to turn the rotor at design speed, the associated rotor heating would be detrimental to concentration performance. Also, local heating at the seal would destroy the seal and probably the shaft too. This is why the rotor was balanced without seals installed. For higher speed and gas operation, the seal drag must be reduced.

One slightly modified original seal was installed in the inlet manifold and operated for about 5 minutes up to $2000 \mathrm{rpm}$. The seal was destroyed, the shaft discolored and the seal housing temperature rapidly increased about $55^{\circ} \mathrm{F}$. This test dramatically demonstrated the need for additional seal alterations.

New lower tension contact seals were procured and further modified. The seal drag was reduced about an order of magnitude. One modified seal was placed in the inlet manifold and successfully operated about 15 minutes up to $9200 \mathrm{rpm}$ without seal or shaft damage. The seal housing temperature increased about $14^{\circ} \mathrm{F}$ which is acceptable. This demonstrated that a low tension, low drag lip seal could operate without differential pressure at reasonably high speed, for a short time without damage. During this test, there was no differential pressure on the seal, and the rotor was at atmospheric pressure.

Most of the measured drag of the new modified seals was due to the three large diameter seals; one each at the two bearings and one at the inlet manifold. Very little drag was measured due to the three small diameter seals in the outlet manifold. Seal drag was measured with a torque wrench at slow rotation. In these discussions, seal drag is assumed constant with shaft speed. The successfully modified seal runs to $9200 \mathrm{rpm}$, asdescribed 


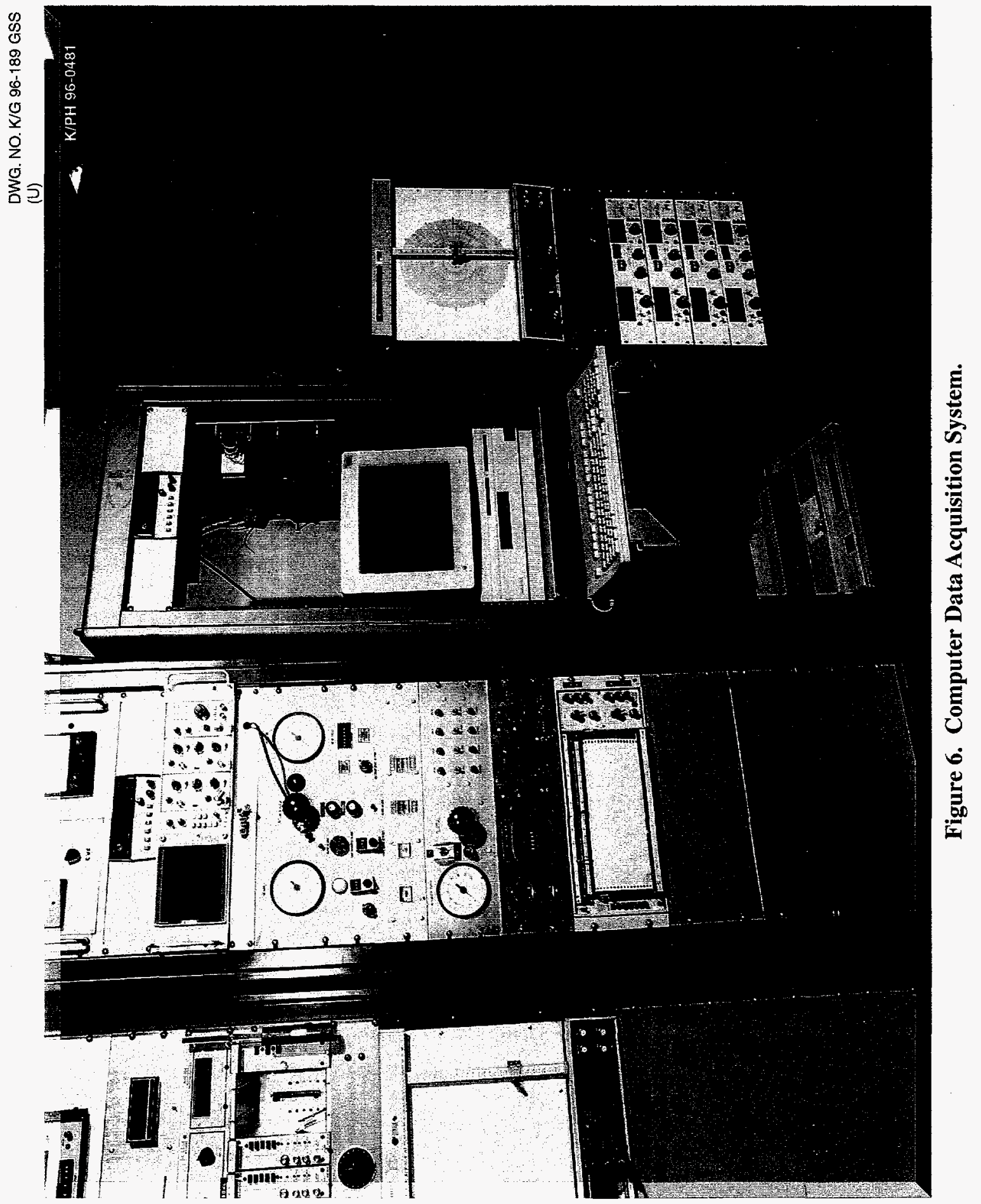


above, suggests that this assumption is valid since there was little difference in maximum achievable speed with or without the seal. At least the drag did not increase with speed.

\section{Seal Pressure Differential}

Seal performance has not yet been demonstrated with the seal under vacuum differential pressure. Lip seal drag (torque) under vacuum was measured at about two $\mathrm{x}$ drag without vacuum.

Drag on the three large modified seals under vacuum was reduced to between $50 \%$ and $75 \%$ of the drive motor capacity. The measured seal drag variation depended somewhat on when the concentrator was reassembled and measured. For a vacuum of 1 torr, windage drag estimates when added to the measured seal drag resulted in a total drag of about $60 \%$ to $85 \%$ of the motor capacity at operating speed. To allow for other drag losses and for some additional margin on motor capacity, it is desirable to achieve vacuum on the rotor exterior of 1 torr or less. It is also desirable to get rotor exterior vacuum below 1 torr by the mechanical forepump before engaging the turbopump to prevent the turbopump from overheating after about $1 / 2$ to $1 \mathrm{hr}$ operation. Some additional vacuum leakage allowance needs to be made for shaft rotation.

The best rotor exterior vacuum achieved (with no shaft rotation) is about 2 torr with the mechanical pump and about 0.6 torr with the turbopump. The best rotor interior vacuum with the mechanical pump is about 0.06 torr. The fact that the rotor interior vacuum is very good indicates that one modified low-drag (inlet manifold) seal is working satisfactorily. It remains only to find the cause of vacuum leakage to the rotor exterior and to make sure the remaining two large seals work as well. If this can be done without having to tighten seals, the rotor should be able to run to full-operating speed.

\section{FOLLOW-ON RECOMMENDATIONS}

\section{Short Term}

Assuming leaks to the rotor exterior can be fixed and the new lip seals prove satisfactory, mechanical testing at design speed and gas concentration performance testing can begin with modest additional funding. If the drag cannot be reduced to acceptable levels with the contact seal approach, new designs will be explored. Our best case scenario assumes resolution of the lip seal drag issue, allowing gas concentration performance testing.

\section{Long Term}

If the use of mechanical lip seals is unsuccessful, an alternate low drag non-contact dry-gas seal design concept has been explored. Although dry-gas seals are currently used in systems with higher pressure differential, experts have indicated applicability to moderate vacuum systems such as in the concentrator. The dry-gas seal would eliminate detrimental local heating and reduce power required to drive the rotor. Use of dry-gas seal technology in the concentrator would require hardware modifications. 


\section{REFERENCES}

1. J. D. Mo", A. J. Szady", "Numerical Prediction of the Separation of the Heavy Components Inside the Trace Gas Centrifuge", Proceedings of the joint ASME and JSME Fluids Engineering Annual Conference, Hilton Head, SC, August 13-18, 1995.

2. J. D. Mo, A. J. Szady, Numerical Modeling of the Flow Fields Inside the Centrifugal Concentrator, Presented at the AIAA 33rd Aerospace Sciences Meeting and Exhibit, Reno, NV, Paper No. AIAA-950701, January 9-12, 1995.

3. J. D. Mo, Numerical Modeling of Trace Gas Concentrator, Final Report, Contract 19X-ST453V, University of Memphis, Mechanical Engineering Department, Memphis, TN 38152, October 1995.

4. A. J. Szady, Centrifugal Concentrator Development Test Unit Status Report, Oak Ridge National Laboratory, Engineering Technology Division, Compiled by D. U. Sheard, Special Projects Office, National Security Program Office, Report No. K/NSP-251, November 1994.

1J. D. Mo, University of Memphis, Memphis, TN

${ }^{2}$ A. J. Szady, Oak Ridge National Laboratory, Oak Ridge, TN 
DISTRIBUTION

Internal

1. Allington, W. J.

2. Andriulli, J. B.

7. Schilling, R. M.

3. Clark H. E.

8. Szady, A. J.

4. Grostick, E. T.

9. Central Research Library

5. Holdaway, R. F.

10. Laboratory Records-RC

6. O'Kain, D. U.

11. Patent Office

\section{External}

11. Van Dyke, W. A., DOE, GNT/NE-20, Germantown/NE-20, 19901 Germantown Road, Germantown, MD 20580

12. OSTI, P. O. Box 62, Oak Ridge, TN 37831 